\title{
Alternative Possibilities, Volitional Necessities, and Character Setting
}

\author{
Benjamin Matheson \\ Stockholm University \\ BIBLID [0873-626X (2017) 45; pp. 287-307] \\ DOI: $10.1515 /$ disp-2017-0008
}

\begin{abstract}
Conventional wisdom suggests that the power to do otherwise is necessary for being morally responsible. While much of the literature on alternative possibilities has focused on Frankfurt's argument against this claim, I instead focus on one of Dennett's (1984) arguments against it. This argument appeals to cases of volitional necessity rather than cases featuring counterfactual interveners. van Inwagen (1989) and Kane (1996) appeal to the notion of 'character setting' to argue that these cases do not show that the power to do otherwise is unnecessary for moral responsibility. In this paper, I argue that their character setting response is unsuccessful.
\end{abstract}

\section{Keywords}

Alternative possibilities, moral responsibility, character setting, volitional necessity, free will

\section{Introduction}

Do we have free will? Are we morally responsible for what we do? Most consider these questions to be linked. If we are morally responsible, then we must have free will. If we have free will, then we may be morally responsible. In other words, free will is thought to be necessary for being morally responsible. But what is free will?

It seems natural to think free will involves a power-namely the power to do otherwise. To have a power to A involves having an ability to A and an opportunity to A. ${ }^{1}$ To have the power to do otherwise than

${ }^{1}$ For more on the distinction between power, ability, and opportunity, see Franklin (forthcoming).

Disputatio, Vol. IX, No. 45, October 2017 
A requires both the ability and opportunity to A and to not-A. Given that free will is necessary for being morally responsible, the power to do otherwise is likewise necessary for being morally responsible.

The claim that the power to do otherwise is necessary for free will and moral responsibility has come under intense critical scrutiny. This claim is no longer considered to be obviously true because of a style of case made popular by Harry Frankfurt (1969). Frankfurt proposed a case where it seems that (a) an agent is morally responsible for an action and (b) the agent lacks alternative possibilitiesthat is, she lacks the power to do otherwise than perform that action. If successful, this case shows that the power to do otherwise is not necessary for being morally responsible. And if free will is necessary for being morally responsible, then this case also shows that free will does not involve the power to do otherwise.

A long and increasingly complicated debate has followed Frankfurt's original paper. Many objections have been raised and many new Frankfurt-style cases have been proposed in response. ${ }^{2}$ In my view, the cases (in particular, Mele and Robb's (1998) blockage cases and Pereboom's $(2001,2014)$ tax evasion case) that seem to avoid the central objections to Frankfurt cases are now so complicated that it is unclear that they elicit the intuition that Frankfurt's original case did. This presents a problem for compatibilists who rely on Frankfurt-style cases to resist the Consequence Argument - a prominent argument against compatibilism (van Inwagen 1983). Without Frankfurt-style cases, such forms of compatibilism are in jeopardy. Such compatibilists must therefore look elsewhere for an argument against the claim that the power to do otherwise is necessary for free will and moral responsibility.

This paper defends an alternative argument against this claimone originally defended by Daniel Dennett (1984). Like Frankfurt, Dennett proposes cases that seem to be counterexamples to the claim that the power to do otherwise is necessary for free will and moral responsibility. And just as Frankfurt-style cases get us to focus on an individual's actual sequence properties, so do Dennett's. But unlike Frankfurt-style cases, Dennett's cases involve no counterfactual interveners but rather feature an agent who can perform only one

${ }^{2}$ For an overview of this debate, see Fischer 2011. 
action in a particular situation because all other courses of action are unthinkable to her. Following Frankfurt (1982), I will call these cases of volitional necessity.

Dennett's argument — which I call the Volitional Necessity Argument - has not been given as much attention as Frankfurt's. Some libertarians have responded to it by claiming that free actions are character setting and arguing that only volitional necessities that are part of a freely set character are ones an individual can be morally responsible for acting from. Peter van Inwagen (1989) and Robert Kane (1996: 38-40) first proposed this kind of approach, but it now seems to be widely accepted (see, e.g., Timpe 2014 and Hartman 2017).

In this paper, I defend the Volitional Necessity Argument from the character setting response. In $\S 2$, I discuss the so-called 'Principle of Alternative Possibilities' (PAP) and discuss how apparent counterexamples to PAP have been used to resist the Consequence Argument. In §3, I outline the Volitional Necessity Argument in more detail. In $\S 4$, I sketch the character setting response. In §5-6, I argue this response is unsuccessful. The upshot is that compatibilists have another viable argument against PAP, and so do not need to rely on Frankfurt-style cases to resist the Consequence Argument.

\section{PAP and the consequence argument}

Compatibilism is the thesis that free will and moral responsibility are compatible with the truth of causal determinism - that is, the thesis that all facts about the past and the laws of nature causally ensure only one future. ${ }^{3}$ But this means that if causal determinism is true then all actions are the product of the past and the laws of nature, and so it seems that an individual lacks the power to do otherwise than she does in the actual sequence of events. The Consequence Argument ${ }^{4}$ is the best expression of this incompatibilist worry:

${ }^{3}$ This definition is based on McKenna's (2012: 13, n. 8).

${ }^{4}$ When formalised, this argument is known as the 'indirect argument'. van Inwagen (1983) proposed three versions of the indirect argument, though each is thought to be independently problematic because they rely on controversial transfer principles - most notorious is the 'beta' principle. Fischer (1994), however, argues that the Consequence Argument still has force when construed without 
If determinism is true, then our acts are the consequences of the laws of nature and events in the remote past. But it is not up to us what went on before we were born, and neither is it up to us what the laws of nature are. Therefore, the consequences of these things are not up to us. (van Inwagen 1983: 16; my emphasis)

That things are 'up to us' is taken to be necessary (and perhaps sufficient) for free will, and for things to be 'up to us' it seems necessary (and perhaps sufficient) that we have the power to do otherwise than we actually do.

Compatibilists have responded to Consequence Argument in two general ways: directly and indirectly. A direct response involves arguing that one of the premises of the argument fails. ${ }^{5}$ An indirect response concedes that causal determinism precludes the power to do otherwise, but claims that this is not a problem for compatibilism. John Martin Fischer (1994) defends such a response. He argues that even if causal determinism precludes the power to do otherwise, it does not preclude the sort of freedom necessary for moral responsibility.

Fischer's indirect response to the Consequence Argument might initially seem surprising since it seems to cut against the conventional wisdom that an individual is morally responsible for an action only if she could have done otherwise than perform that action. In other words, it seems obvious that alternative possibilities are a necessary condition on moral responsibility. Fischer's response appeals to Frankfurt's apparent counterexamples to PAP, such as the following:

Suppose someone - Black, let us say — wants Jones to perform a certain action. Black is prepared to go to considerable lengths to get his way, but he prefers to avoid showing his hand unnecessarily. So he waits until Jones is about to make up his mind about what to do, and he does nothing unless it is clear to him (Black is an excellent judge of such things) that Jones is going to decide to do something other than what he wants him to do. If it does become clear that Jones is going to decide to do something else, Black takes effective steps to ensure that Jones decides to do, and

transfer principles.

${ }^{5}$ Humean compatibilists, for example, argue that the fixity of laws of nature is false. On their view, the laws of nature are only settled at the end of time. See Beebee and Mele 2002. 
that he does do, what he wants him to do. (Frankfurt 1969: 835)

The 'effective steps' that Black takes are to 'manipulate the minute processes of Jones' brain and nervous system in some ... direct way, so that causal forces running in and out of his synapses and along the poor man's nerves determine that he chooses to act and that he does act in the one way and not in any other' (Frankfurt 1969: 835-836). This 'direct way' might involve Black activating a pre-implanted chip in Jones' brain that forces Jones' to act in the manner that Black desires. Suppose that Black wants Jones to kill Walter and that Jones kills Walter without Black having to intervene. Is Jones morally responsible for killing Walter? It seems that he is. Even though Black wants Jones to do so, Black is no way involved in bringing about Jones' action. Black is a 'counterfactual intervener' which means that he will only compel Jones to kill Walter if it seems that Jones is not going to kill him. However, in his capacity as a counterfactual intervener Black stops Jones from having the power to do otherwise, because if Jones showed any sign that he would do otherwise, Black would have intervened and compelled him to kill Walter. Thus, it seems that we continue to judge that an agent is morally responsible even if she lacks alternative possibilities. Hence PAP is false.

But there are problems with Frankfurt's case - in particular, the need for Jones to show a 'prior sign' to indicate that he is going to do otherwise. Most agree that Frankfurt's original case does not work for this or another reason. There are new Frankfurt-style cases but, as I've said, I think that these are now so complicated that it is not clear we get the intuition that we got from Frankfurt's original case. For the purposes of this paper, I will simply assume that Frankfurtstyle cases are not counterexamples to PAP. I will also assume in this paper that direct responses are untenable, since they either involve denying the fixity of the past or the fixity of the laws. Given this, compatibilists are without a response to the Consequence Argument. Before considering an alternative argument against PAP, we must get clear on which sense of PAP is targeted by this argument.

Frankfurt's case is supposed to target a general version of PAP -namely:

PAP. An individual is morally responsible for A only if she could have done otherwise than A. 
This version of PAP is neutral between compatibilist and libertarian senses of the 'could have done otherwise'. However, in order to defeat the Consequence Argument, compatibilists do not need to argue that alternative possibilities simpliciter are not necessary for free will. Rather, they need only show that alternative possibilities in the sense required by libertarians are not necessary for free will. We might therefore distinguish between the following two senses of PAP:

$\mathrm{PAP}_{\mathrm{P}}$. An individual is morally responsible for $\mathrm{A}$ only if is she had the power to do otherwise than A.

$\mathrm{PAP}_{\mathrm{A}}$. An individual is morally responsible for A only if she had the ability to do otherwise than A.

PAP $_{P}$ expresses the thesis that moral responsibility requires that an individual could do otherwise than $\mathrm{A}$ in the actual sequence of events. So, given the same laws of nature and the facts about the past, the agent had the power to do otherwise than $\mathrm{A} . \mathrm{PAP}_{\mathrm{A}}$ expresses the weaker thesis that moral responsibility requires that an individual could do otherwise than A but not in the actual sequence of events. Merely having an ability does not require than individual can actually exercise that ability. We can work out whether an individual could have done otherwise than $\mathrm{A}$ at $t_{1}$ in this sense if we imagine things were slightly different (that is, we imagine a nearby possible world); the individual has the ability to do otherwise in the actual sequence of events if she would have done otherwise in a close alternative sequence of events (that is, a nearby possible world).

All compatibilists need is an argument against $\mathrm{PAP}_{\mathrm{P}}$ because it is only this principle that expresses the thesis that the libertarian sense of 'could have done otherwise' is necessary for moral responsibility. And it is this sense of 'could have done otherwise' that the Consequence Argument seems to show will not obtain if causal determinism is true. If $\mathrm{PAP}_{\mathrm{P}}$ is false, then even if the Consequence Argument shows that we lack the power to do otherwise, it does not show that we lack the kind of freedom necessary for moral responsibility. So if $\mathrm{PAP}_{\mathrm{P}}$ is false, then compatibilism can resist the force of the Consequence Argument. 


\section{The volitional necessity argument}

As he nailed his theses to the door of the church and thereby initiated the reformation, Martin Luther is said to have proclaimed: 'Here I stand. I can do no other'. Dennett (1984: 133) asks us to suppose that Luther lacked the power to do otherwise than he did at that time. Would this mean that Luther was not morally responsible for so acting? Dennett says no. The fact that Luther lacked the power to do otherwise at this time does not mean that he lacks moral responsibility for his action at that time. What is relevant to moral responsibility, according to Dennett, are Luther's reasons for acting, and not whether he had the power to do otherwise. Luther lacks the power to do otherwise at this time because his conscience has ruled out any alternative course of action. According Dennett, all other courses of action at that time are unthinkable to Luther.

I do not think that 'unthinkability' properly identifies the phenomenon at issue in the Luther case. We can sometimes think about doing things that we could never actually do. This is something that happens to those who live with intrusive thoughts. These thoughts can be disturbing and misleading, but most of those who get such thoughts will never act on them. A person might think about A-ing and yet she is a person such that she will never A. Following Frankfurt (1982), I propose that we instead refer to Luther's action as stemming from volitional necessity. ${ }^{6}$

If $\mathrm{A}$ is volitionally necessary for an individual at $t_{1}$, then the individual cannot do otherwise than A at $t_{1}$. Notice that volitional necessities are relativized to particular times. What is distinctive about a volitional necessity is that while the agent lacks the power to do otherwise, she still seems to be unlike non-responsible agents who seem to lack the power to do otherwise. An unwilling addict, for example, is someone who acts from strong or compulsive desires and yet does not want to be moved by those desires. When we act from volitional necessities, however, we want to be moved by those desires. Indeed, it is our very identity as agents that makes us want

\footnotetext{
${ }^{6}$ See also Williams' (1995) notion of 'moral incapacity'. See Watson 2004 for discussion of volitional necessities and moral incapacity. I construe 'volitional necessity' more broadly than Watson does in this paper.
} 
to be moved by them.

Moreover, volitional necessities do not render agents unable to do otherwise in all senses. Notice that there is a sense in which Luther could have done otherwise. If he had not wanted to protest the extravagances of the Catholic Church, then he would have not nailed his theses to the door. It was only in his particular circumstances that Luther found that he could no other than protest. What seems clear is that Luther lacks alternative possibilities in the following sense: he lacks the power to do otherwise when he acted - that is, while he might have been able to do otherwise, he lacked the opportunity to do otherwise. His conscience (in effect) blocked his opportunities to exercise his ability to act otherwise. Indeed, we might best characterise volitional necessities not as undermining the ability to do otherwise, but rather as precluding the opportunity to exercise that ability. Given that Luther is morally responsible, if free will is necessary for moral responsibility then it seems he must exercise free will at that time too. Since we seem to have a case of free will and moral responsibility without the power to do otherwise being exercised, it seems that the power to do otherwise is not necessary for free will and moral responsibility. For ease of expression, I will henceforth use 'alternative possibilities' to refer only to having the power do otherwise. $^{7}$

Dennett goes on to argue that this sort of case is not rare either because we all have volitional necessities - that is, there are many instances where only one course of action is available to us and yet we still seem to be exercising responsible agency. Using himself as an example, Dennett claims that it is impossible for him to torture an innocent person for a thousand dollars at a particular point in time. Of course, we might imagine a scenario where 'space pirates' hold 'the whole world to ransom' and promise not to destroy it if Dennett tortures an innocent person for a thousand dollars (Dennett 1984: 133). Dennett accepts that he would likely torture an innocent in this

\footnotetext{
${ }^{7}$ What might confuse things is that 'ability' is often used to refer to 'ability' in the sense used in the text and to refer to 'power'. Once we separate the notion of 'opportunity', we can see the difference between ability and power. I follow Franklin (forthcoming) in making these distinctions. Others distinguish between 'wide' and 'narrow' ability (Vihvelin 2013) or 'general' and 'specific' ability (Mele 2003).
} 
scenario. However, this is a different scenario to the original onethat is, the original scenario featured no space pirates - so it does not affect his claim regarding his volitional necessities. Again, volitional necessities are specified to particular situations.

This is important to emphasise because the libertarian claims that to act freely and therefore be morally responsible for our actions we must have the power to act differently in exactly the same scenario. As noted, cases of volitional necessity are only attempting to show that the power to do otherwise is not necessary for free will or moral responsibility, where power requires ability and opportunity. It is uncontroversial that agents can often act differently in different situations - that is, that they have an ability to act otherwise - and nothing about these cases suggests otherwise.

Again, given that we judge that Luther is morally responsible when he acts and he plausibly lacks alternative possibilities at that time, it seems that the power to do otherwise is not necessary for moral responsibility. Consequently, given that free will is necessary for moral responsibility, it seems this power to do otherwise is not necessary for free will either. Our judgement that Luther is morally responsible seems to be based on his actual sequence properties. Hence, it seems that free will and moral responsibility are actual sequence concepts.

\section{Character setting libertarianism}

We can summarise Dennett's volitional necessity argument as follows:

(1) We are morally responsible for actions that stem from volitional necessities.

(2) If alternative possibilities are necessary for moral responsibility, then we are not morally responsible for actions that stem from volitional necessities.

Therefore,

(3) Alternative possibilities are not necessary for moral responsibility.

(4) Free will is necessary for moral responsibility. 
Therefore,

(5) Alternative possibilities are not necessary for free will.

This argument is valid and its premises seem true. Premise 1 is supported by Dennett's cases. Premise 2 seems to follow from PAP and the acknowledgement that volitional necessities block alternative possibilities. Premise 3 follows from premises 1 and 2. Premise 4 is more controversial, but at least libertarians will typically agree that it is true. The overall conclusion follows from premises 3 and 4. Premise 3 states that there are cases of moral responsibility without alternative possibilities and premise 4 states that there are no cases of moral responsibility without free will, so there must be some cases of free will without alternative possibilities; hence alternative possibilities are not necessary for free will. The first stage of the argument (1-3) is an argument against $\mathrm{PAP}_{\mathrm{P}}$, and the overall argument supports a claim about the nature of free will — namely that it does not require alternative possibilities, i.e. that it is an actual sequence concept.

Libertarians have two options in response to this argument. They can either deny premise 1 or premise 2. (Denying premise 4 might be possible for some libertarians who hold that free will is not necessary for moral responsibility, but I set aside such libertarians in what follows.) A libertarian who denies premise 1 has two options. First, bite the bullet and insist that Luther is not morally responsible contrary to our intuitions. Second, argue that Luther in fact has alternative possibilities. Whether or not denying premise 1 is a plausible strategy is not a question I will take up here.

Those libertarians who have engaged with Dennett's argument have rejected premise 2. Such libertarians accept that alternative possibilities are necessary for moral responsibility, but they deny that this means we are not morally responsible for actions that stem from volitional necessity. To make sense of this, these libertarians appeal to the notion of character setting. Roughly, the idea is that volitional necessities form part of or are a 'set' character - that is, a character that only allows an agent to perform particular sorts of actions at particular times. ${ }^{8}$ On this view, Luther has a set character such that

${ }^{8}$ Those who have issues with the notion of 'character' might worry about 
he cannot help but initiate the reformation at that time. According to such Character Setting Libertarianism (CSL), Luther is morally responsible for acting from that set character, and the volitional necessities it includes or that constitute it, as long as he freely set his own character. To freely set one's own character, an agent must have alternative possibilities (in the sense of having the power to do otherwise) at some point during her history. So, Luther is morally responsible for initiating the reformation because his action traces back to an earlier free action (or set of free actions) - that is, a time when he had the power to do otherwise. This earlier free action (or set of free actions) set Luther's character such that he had certain volitional necessities such that he lacked the power to do otherwise than initiate the reformation when he did so. Hence, even though Luther lacked alternative possibilities when he initiated the reformation, he is still morally responsible because he, in effect, inherits moral responsibility from his earlier free and morally responsible action at which time he did have alternative possibilities.

As Kane puts it:

If Luther's affirmation did issue inevitably from his character and motives at the time it was made, then his moral accountability for it would depend on whether he was responsible for being the sort of person he had become at that time (1996: 39).

On this view, we might say that Luther is derivatively morally responsible. It is only for directly morally responsible actions that an action requires alternative possibilities, on this view. Kane is open to the idea that Luther has derivative freedom. That is, the agent still acts freely when she acts from volitional necessities because those actions inherit their freedom from an early directly free action, where directly free actions require alternative possibilities. ${ }^{9}$

van Inwagen, it seems, is not open to the idea that Luther has derivative freedom. According to van Inwagen's (1989) version of CSL,

this way of phrasing this response. However, my argument can be translated into terms that do not require the notion of 'character'. So I set aside such worries in what follows.

${ }^{9}$ Indeed, the notion of 'derivative' or 'indirect' freedom or free will has been embraced by other authors. See, for example, Timpe 2014, Hartman 2017: 7880, 134-5, Franklin (forthcoming). 
it turns out that we rarely exercise free will because we rarely have alternative possibilities. In other words, we do not have free will at $t_{1}$ if we do not have alternative possibilities at $t_{1}$. van Inwagen argues that the rarity of alternative possibilities is an implication of 'Rule Beta' - the central inference principle in one formal version of his Consequence Argument. It follows from this principle, according to van Inwagen, that even if determinism is false people rarely have the power to do otherwise, but it does not follow that people never have alternative possibilities.

There are sufficient similarities between van Inwagen's and Kane's responses to Dennett's argument that I shall discuss them together, and I will refer to them as different types of CSL. On this view, if an agent freely sets her character - which includes her volitional necessities - she may be morally responsible for the upshots of that character. In the rest of the paper, I discuss two problems for CSL. The first is the superstructure problem, and the second is the foundation problem.

\section{The superstructure problem}

The first problem for CSL is analogous to a problem for foundationalism about epistemic justification. According to foundationalism, propositions expressed by beliefs are either justified by other propositions or they are self-justified. The superstructure problem is a problem for classical foundationalism. According to classical foundationalism, only beliefs that express self-evident propositions are self-justified (i.e. basic or foundational). But it seems hard, if not impossible, to explain how such beliefs (like the belief that you exist) confer justification on everyday beliefs (like the belief that you are currently reading this paper) that we intuitively take ourselves to be justified in having. In short, it is not clear that we can trace back from our everyday beliefs to self-justified beliefs. So, it looks as if classical foundationalism cannot explain how many of our everyday beliefs are justified. ${ }^{10}$

CSL has a similar problem. It is not clear that this view can explain

${ }^{10}$ See Williams 2001: 85 for more on the superstructure problem for classical foundationalism. 
how we are morally responsible for all the actions we intuitively take ourselves to be morally responsible for. Specifically, it is not clear CSL can accommodate the intuition that we always act freely and are morally responsible for actions that stem from volitional necessities. We can also put the problem in terms of tracing. It is not clear that we can always trace back from an action that stems from a volitional necessity to an undetermined decision - that is, a decision that the individual has the power to do otherwise than make, and also what the CSL holds (either partly or wholly) constitutes a free action. ${ }^{11}$ Take Luther, for example. The CSL's move is to claim that Luther's action (of initiating the reformation) might trace back to an undetermined decision. However, there is no guarantee that it does. The CSL must contend that we would change our judgement about Luther if we discovered that he never had an undetermined decision. But it is not clear that this is true. And even if it is true that Luther had an undetermined decision, it is not at all clear that this is true of other agents who act from volitional necessities. ${ }^{12}$ Yet, it seems to

${ }^{11}$ I assume, for the sake of argument, that undetermined decisions grant or can grant the power to do otherwise. However, I take the problem of present or cross-world luckiness for libertarians calls exactly this into question. Suppose we have two possible worlds, $w_{1}$ and $w_{2}$, that are identical (same laws, same past) until $t_{1}$. At $t_{1}$ in $w_{1}$, an individual As. At $t_{1}$ in $w_{2}$, the individual (or her counterpart) Bs. It seems that whether the individual As or Bs is arbitrary or lucky. Intuitively, such luck is freedom and responsibility undermining or mitigating, and so it seems that a decision merely being undetermined does not provide the individual with the power to do otherwise. Just because things might go differently does not mean the individual has power over whether it goes differently. As noted, I set aside this problem in what follows. See Franklin (forthcoming) for discussion of the various forms of this problem of luck for libertarians.

${ }^{12}$ A related problem, though one I set aside here, is that we would also need to be able to foresee that setting our character one way rather than another would leading to certain sorts of actions. Vargas (2005) proposes a series of cases that suggest that apparently character-setting actions are not ones where we can also foresee the relevant upshots of those actions. See Fischer and Tognazzini 2009 for a response to Vargas, though note that they propose this response from the perspective of Fischer's actual sequence compatibilist account of moral responsibility. It is not clear this reply can be used by CSLs because there are many plausibly occasions when an agent exercises her actual sequence compatibilist (that is, reason-responsive) capacities, but there are not many plausible occasions when an agent has a (genuinely) undetermined decision. 
remain intuitively plausible that such agents are morally responsible for acting from such necessities.

Defenders of CSL might just bite the bullet here and claim that we are not morally responsible for acting from volitional necessities unless those volitional necessities are part of our freely set character. However, this means that if CSL is true then we may be much less morally responsible than we intuitively take ourselves to be. Typically, libertarianism is seen as satisfying our ordinary conception of ourselves as morally responsible agents who are morally responsible for much of what we do. But according to CSL, we are potentially forced to revise this ordinary conception. ${ }^{13}$

Note two things about CSL. First, according to this view, anyone who has never had an undetermined decision is not morally responsible for her actions. Second, these undetermined decisions must be genuine and not merely apparent undetermined decisions. As van Inwagen (1989: 414) discusses, sometimes when a person thinks she has an undetermined decision it is not the case that she really has an undetermined decision to make. Rather, she just does not know what she wants and goes through a process phenomenologically similar, but metaphysically different, to an undetermined decision in an effort to work out what she wants. These apparent undetermined decisions, then, are not times when an agent has alternative possibilities. They are more properly described as instances of self-discovery rather than self-making.

These two points create epistemic difficulties for CSL. First, we do not typically check if an agent has had an undetermined decision before we attribute moral responsibility to her. Of course, according to CSL, we would revise our attribution of moral responsibility if we learnt that an agent did not have an undetermined decision. But it does not seem clear that this is true. Indeed, I would wager that it is not true for most people. Second, even if we did check and would revise our judgement if a person had never had an undetermined decision, it seems that we have no way to differentiate between a genuine

${ }^{13}$ We should be careful to distinguish between two forms of revisionism about moral responsibility. The first is revisionary about the concept of moral responsibility. This is the kind of view defended by Vargas (2013). The other is revisionary about the practice of moral responsibility. My point is that CSLs seem to committed to revisionism in the latter sense. 
undetermined decision and an only apparent undetermined decision.

Dennett's overall argument against $\mathrm{PAP}_{\mathrm{P}}$ includes two epistemic arguments related to the points I have made here. I believe that his epistemic arguments constitute another promising avenue for compatibilists to resist $\mathrm{PAP}_{\mathrm{P}}$. In this paper, however, I wish to concentrate only on the Dennett's metaphysical argument against $\mathrm{PAP}_{\mathrm{P}}-$ namely, the Volitional Necessity Argument. It seems that CSLs can resist this argument on metaphysical grounds - that is, they can just claim that CSL is a view about what is the case, and not argue against what we can know is the case. So it might be that people are morally responsible, even though we measly humans can never know this. I think that this exposes the gulf between the CSL's conception of moral responsibility and the conception of moral responsibility implicit in our actual practice of holding one another responsible. But, again, I set aside such points here.

\section{The foundation problem}

As we'll see in this section, CSL holds that undetermined decisions determine whether an agent's character will be set one way rather than another. So if an agent chooses to act from values V1 over V2 (where V1 and V2 are incommensurable), then her character will be set such that she acts only on V1 and not V2 in future. So CSL claims that there is some causal connection between an undetermined decision and a set character. In this section, I argue the CSL has a foundation problem. I argue CSL is unable to explain how the connection between an undetermined decision and a set character is one the individual can have power over with the consequence that undetermined decisions are not the right foundation for a freely set character; hence, CSL cannot accommodate the intuition that we are morally responsible for acting from volitional necessities. This foundation problem is made up of two subproblems: the connection problem and the self-dissolution problem. I discuss these in turn.

The Connection Problem

Let's start with the following story from Kane:

[A business woman] is on her way to an important meeting when she 
observes an assault taking place in an alley. An inner struggle ensues between her conscience, to stop and call for help, and her career ambitions, which tell her she cannot miss this meeting. She has to make an effort of will to overcome the temptation to go on. If she overcomes this temptation, it will be the result of her effort, but if she fails, it will be because she did not allow her effort to succeed. And this is due to the fact that, while she willed to overcome temptation, she also willed to fail, for quite different and incommensurable reasons. When we, like the woman, decide in such circumstances, and the indeterminate efforts we are making become determinate choices, we make one set of competing reasons or motives prevail over the others then and there by deciding. (2007: 26-27)

Kane's view is that our decision is the thing that sets our characters a particular way. He writes: 'We set our wills one way or the other in the act of deciding itself, and not before' (2007: 30; my emphasis). So if the businesswoman overcomes temptation and helps stop the assault, then she becomes the sort of person who does this more regularly. And if she succumbs to temptation and does not help, then she will become (more) hard-hearted.

This case provides some prima facie support for the claim that there is a connection between undetermined decisions and a set character. If the businesswoman later acts altruistically or hardheartedly, then we can perhaps trace this back to her undetermined decision to either act altruistically or hard-heartedly. But what is the nature of this causal connection? I will now argue that it is not a necessary connection. That is, it is possible for a person to have an undetermined decision between A-ing and B-ing, decide to A, and yet not be disposed to $A$ at all in future. Consider the following version of the businesswoman case.

A stranger approaches the businesswoman and asks for her assistance to help restrain the assailant. The businesswoman agrees and goes down the alley. By the time she realises what is happening, it's too late: it's a trap! The three strangers mug her. They threaten to hurt her if she does not immediately hand over her valuables. She duly complies. She is mildly traumatised by this event, though not physically hurt. The worse thing, she thinks afterwards, is that she thought she was helping someone else but that person really wanted to harm her. After this, she never helps people again because, as she 
sees it, people are only out for themselves and it is just not worth the risk to try to help people. It seems entirely plausibly that the businesswoman has an undetermined decision to act from one set of values, V1, but then because of the events that occur afterwards, her character is not set such that she will not act from V1 in future.

One worry might be that the woman has another undetermined decision during or after being assaulted herself. But this need not be the case. Indeed, let us stipulate that it is not the case. Another worry might be that the businesswoman is determined by the events that happen to her after the undetermined decision to have the character she later does. But this need not be true. For one thing, her decision to help the person she thought was being mugged was undetermined and this plays some causal role in her resulting character - namely it is because she chose to be altruistic and because that backfired that she ended up becoming hard-hearted. And being assaulted need not have certain effects. We can imagine a third version of the businesswoman case where she decides to be altruistic, she is mugged, but then becomes an altruistic person. So it is not true that traumatic experiences such as this must determine a person's character to be a particular way. Hence, it is plausible that the businesswoman's character was not determined by the events after her undetermined decision.

In the first and third versions of the businesswoman case, we are told that the woman's character is set in the way that she decidese.g. she chooses to act from altruistic values and then comes to only act from altruistic values. But in the second version, the businesswoman's character is set differently from how she decides-e.g. she chooses to act from altruistic values but then comes to only act from egoistic values. So there seems to be no necessary connection between having an undetermined decision and then having one's character set a particular way. While the undetermined decision still might be causally involved in a person's character being set, how the person decides does not seem to determine how her character will be set because, as we've seen, it can easily be set other than how the person decides.

Sometimes, of course, a person's character is set in a way that matches her undetermined decision. But it seems to be lucky or arbitrary whether this happens. This luckiness or arbitrariness in the 
connection between an undetermined decision and a set character undermines the claim that it is up to the person how her character is set. Such luckiness seems clearly to be at odds with the claim that the person has power over how her character is set. So even if an agent's character is set following her undetermined decision in favour of one set of values, the agent does not freely set her character that way. At the very least, we have not yet been given any reason to think that this is the case. ${ }^{14}$

Of course, a defender of CSL might say that undetermined decisions do not necessarily set an agent's character but rather merely increase the likelihood that an agent's character will be set one way rather than another. So if an agent chooses to act from V1 rather than V2 (where V1 and V2 are incommensurable), then she will be more likely to act from V1 in future. Eventually she will have chosen to act from V1 over V2 sufficient times such that her character will be set such that she only acts from V1 in future. This does not actually avoid the problem of connection-luckiness that I have identified because the connection between the final undetermined decision (that is, the decision prior to the agent's character being set) and the agent's character being set a particular way still seems lucky. This kind of move also exposes an even deeper problem for the CSL.

\section{The Self-Dissolution Problem}

It is an implicit assumption of CSL that undetermined decisions reduce the amount of undetermined decisions a person will have in future, and thus undetermined decisions are conducive for character setting. It is either the case that an undetermined decision immediately settles what an agent's character will be like or an undetermined decision makes it increasingly likely that an agent's character will be set a particular way. However, CSL does not provide an argument for even the latter disjunct. It might well be that an undetermined decision leads to further and increasingly diverse undetermined decisions. So rather than undetermined decisions being instances of

\footnotetext{
${ }^{14}$ Note that the problem of luck I have identified for the CSL is different from the problem of cross-world luckiness typically pressed on libertarians. See fn. 11 for more on this other problem of luck.
} 
self-making, they might actually be instances of self-dissolution. A literary example will help illustrate the point.

The Dice Man describes the story of a psychiatrist who, after being depressed about all his actions being determined by his character, starts to make all his decision on the basis of dice rolls. For each decision, he assigns numbers to dice. We might imagine he faces a similar decision that the businesswoman faces. We can suppose that he says that if he rolls 2-6, then he will help the person being mugged, and that he says that if he rolls 7-12, then he will not help the person being mugged. In effect, the dice man outsources his decision-making to the dice. What is interesting about this story is that each dice roll does not make the dice man's character more firm or resolute. Each time he decides to use the dice it in fact increases the options he has available. Eventually, his character slowly dissolves until there seems to be no restriction to what he might do, morally and otherwise.

This suggests that undetermined decisions could lead to more, not less, undetermined decisions. We have reason to believe that undetermined decisions are just not the sort of thing that can, even in principle, set an agent's character one way rather than another. In other words, undetermined decisions are not the right foundation for a set character. I should say, though, that I do not think this case decisively shows that undetermined decisions always lead to more rather than less undetermined decisions or that undetermined decisions cannot be followed by a person's character being set a particular way. All this case does is call into doubt the implicit assumption that is central to CSL: namely, that undetermined decisions are (at the very least) conducive towards character setting. We have no reason to agree with that claim. So, even if undetermined decisions are free actions, we have no reason to think that they even increase the likelihood that an agent's character will be set, let alone set a particular way; indeed, they might even have the opposite effect. In other words, we have no reason to think that free actions are also character setting actions.

The upshot is this: the CSL cannot accommodate our intuitions about volitional necessity cases. Recall the dialectic. Dennett proposes cases of volitional necessity as counterexamples to PAP. CSL tries to accommodate these cases by claiming that agents are morally responsible for actions that stem from volitional necessity only when 
those necessities are part of a freely formed character (that is, a character that has been set as a result of the agent's undetermined decisions). I then argued that there is no non-lucky connection between an undetermined decision and an agent's character being set in a particular way. Moreover, we have no reason to believe undetermined decisions even increase the likelihood an agent's character being set a particular way. Hence undetermined decisions are not the right foundation for a set character. CSL therefore cannot explain why we are morally responsible for actions that stem from volitional necessity, and hence does not accommodate our intuitions about volitional necessity cases. Dennett's argument remains a powerful argument against $\mathrm{PAP}_{\mathrm{P}}$. Compatibilists therefore no longer need to rely on Frankfurt's argument to undermine $\mathrm{PAP}_{\mathrm{P}}$, and in turn to undermine the Consequence Argument. We have good reason to conclude that alternative possibilities are not necessary for either free will or moral responsibility.

Of course, as noted, this argument only applies to $\mathrm{PAP}_{\mathrm{P}}$ - that is, the principle that expresses the thesis that the power to do otherwise is necessary for moral responsibility. It remains that alternative possibilities in another sense - such as having the ability to do otherwise - might be necessary for free will and moral responsibility. But, again, for compatibilists to resist the Consequence Argument, they need not make the stronger claim that the ability to do otherwise is unnecessary for free will and moral responsibility. It might turn out, though, that this ability is not necessary for free will or moral responsibility, or that possessing this ability does not make us free or morally responsible, but that is not a question I have touched upon here. ${ }^{15}$

Benjamin Matheson Stockholm University, Stockholm, Sweden benjamin.matheson@philosophy.su.se

\footnotetext{
${ }^{15}$ This paper was first presented at a workshop on Free Will and Alternative Possibilities at the University of Valencia in September 2016. Thanks to Pablo Rychter and Josep E. Corbí for organising this workshop. Thanks to the participants for their comments and feedback. Thanks also to an audience at the University of Gothenburg for their comments and feedback. Thanks to Robert Hartman for written feedback.
} 


\section{References}

Beebee, Helen and Mele, Alfred R. 2002. Humean compatibilism. Mind 111 442: 201-223.

Dennett, Daniel. 1984. Elbow Room: The Varieties of Free Will Worth Wanting. MIT Press

Fischer, John Martin 1994. The Metaphysics of Free Will: An Essay on Control. Blackwell.

Fischer, John Martin. 2011. Frankfurt-type examples and semicompatibilism: New Work. In Oxford Handbook of Free Will ( $2^{\text {nd }}$ Edition), ed by Robert Kane. Oxford: Oxford University Press.

Fischer, John Martin and Tognazzini, Neal. 2009. The truth about tracing. Noûs 43(3): 531-556.

Frankfurt, Harry. 1969. Alternate possibilities and moral responsibility. Journal of Philosophy 66(3): 829-839.

Frankfurt, Harry. 1982. The importance of what we care about. Synthese 53(2): 257-272.

Franklin, Christopher. Forthcoming. A Minimal Libertarianism: Free Will and the Promise of Reduction. Oxford: Oxford University Press.

Hartman, Robert J. 2017. In Defense of Moral Luck: Why Luck Often Affects Praiseworthiness and Blameworthiness. Routledge.

Kane, Robert. 1996. The Significance of Free Will. Oxford: Oxford University Press.

Kane, Robert. 2007. Four Views on Free Will, ed. by M. Vargas et al. Oxford: Blackwell.

McKenna, Michael. 2012. Conversation and Responsibility. Oxford: Oxford University Press.

Mele, Alfred R. and Robb, David. 1998. Rescuing Frankfurt-style cases. Philosophical Review 107(1): 97-112.

Mele, Alfred R. 2003. Agents' abilities. Noûs 37: 447-70.

Pereboom, Derk. 2001. Living Without Free Will. Cambridge: Cambridge University Press.

Pereboom, Derk. 2014. Free Will, Agency, and Meaning in Life. Oxford: Oxford University Press.

Timpe, Kevin. 2014. Free Will in Philosophical Theology. Bloomsbury Academic. van Inwagen, Peter. 1983. An Essay on Free Will. Oxford University Press: Oxford. van Inwagen, Peter. 1989. When is the will free. Philosophical Perspectives 3: 399-422. Vargas, Manuel. 2013. Building Better Beings: A Theory of Moral Responsibility. Oxford University Press.

Vargas, Manuel. 2005. The trouble with tracing. Midwest Studies in Philosophy 29(1): 269-291.

Vihvelin, Kadri. 2013. Causes, Laws and Free Will. Oxford: Oxford University Press. Watson, Gary. 2004. Agency and Answerability: Selected Essays. Oxford University Press. Williams, Bernard. 1995. Making Sense of Humanity. Cambridge University Press: Cambridge.

Williams, Michael. 2001. Problems of Knowledge: A Critical Introduction to Epistemology. Oxford University Press. 